\title{
Photocatalytic Palladium-Catalyzed Fluoroalkylation of Styrene Derivatives
}

\author{
Réka Adamik, Tamás Földesi, and Zoltán Novák*
}

Cite This: Org. Lett. 2020, 22, 8091-8095

Read Online

ABSTRACT: A visible light induced palladium-catalyzed fluoroalkylation method was developed. The Heck-type alkyl coupling reaction enables the introduction of trifluoroethyl, difluoroethyl and other fluoroalkyl fragment into styrenes under mild reaction conditions without the use of additional photosensitizers and ensures access to fluoroalkylated olefins on a broad scale.

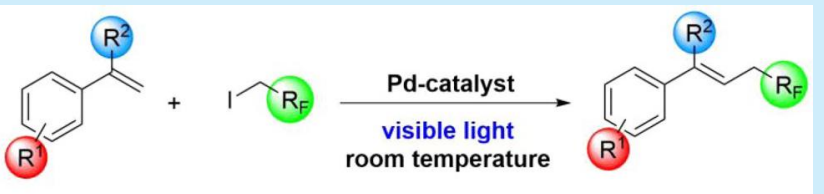

45 examples up to $86 \%$ isolated yield

$\mathrm{T}$ he introduction of fluorine-containing functional groups into organic molecules and drug candidates can often improve the enzymatic oxidative and thermal stability as well as increase the lipophilicity and bioavailability of molecules. ${ }^{1}$ Therefore, in recent years the development of fluoroalkylating methods and reagents, especially trifluoromethylation ${ }^{2}$ and trifluoroethylation, ${ }^{3}$ has become an emerging area, including the photocatalytic transformations. ${ }^{4}$

Besides the fluoroalkylation of aromatic and heteroaromatic rings, the installation of short fluoroalkyl chains into terminal alkene is also important, but is a less explored transformation, which is mostly limited to perfluoroalkylation ${ }^{5}$ and trifluoroethylation. There are several different strategies to construct the trifluoroethylated styrene structure. It can be synthesized by nucleophilic substitution from the corresponding allylbromide derivative, ${ }^{6}$ oxidative trifluoromethylation, ${ }^{7}$ classical transition metal coupling with vinyl-boronates, ${ }^{8}$ or photocatalytic transformation ${ }^{9}$ using the corresponding fluoroalkyl halides as coupling agents.

In continuation of our studies in the field of fluoroalkylation reactions ${ }^{3 a, b, 10}$ and photocatalytic transformations, ${ }^{11}$ we aimed to take advantage of the photo-Heck-type coupling approach to introduce more versatile fluoroalkyl groups into the styrene moiety using palladium catalysis and visible light irradiation (Scheme 1). The classical palladium catalyzed cross-coupling reaction $^{12}$ involves a well-established two-electron redox mechanism typically between the $\mathrm{Pd}(0) / \mathrm{Pd}(\mathrm{II})$ oxidation states. However, using the original Heck reaction for the coupling of unactivated alkyl halides with aryl-alkenes is challenging because of two factors: ${ }^{13}$ the oxidative addition step is relatively slow with low-valent transition metals, and the resulting alkylmetal species can undergo premature $\beta$-hydride elimination which leads to side products. These disadvantages can be eliminated by photoexcitation of the applied catalyst. ${ }^{14}$ The photoexcited Pd-complexes can participate in a singleelectron transfer (SET) mechanism to generate a $\mathrm{Pd}(\mathrm{I})$ species, which allows the desired coupling to occur selectively in a photocatalytic manner. Two possible catalytic methods are
Scheme 1. Aim: Direct Fluoroalkylation of Styrene Derivatives

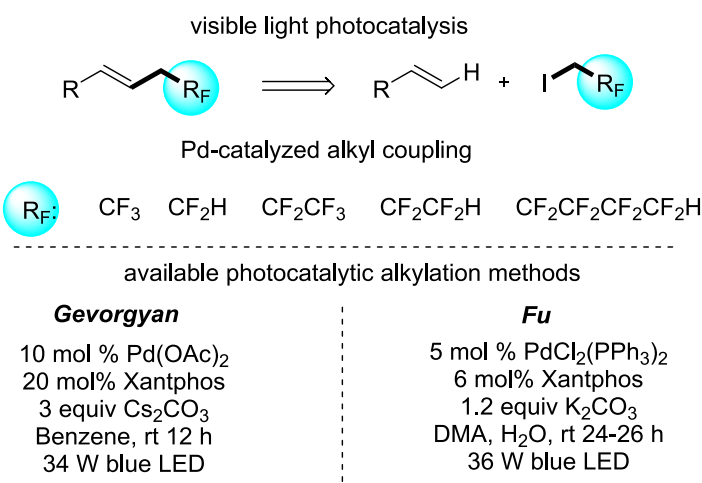

available to achieve the desired functionalization with fluoroalkyl species (Scheme 1). The Gevorgyan method is based on the $\operatorname{Pd}(\mathrm{OAc})_{2} /$ Xantphos catalytic system, and the transformation works efficiently in benzene in the presence of $\mathrm{Cs}_{2} \mathrm{CO}_{3} \cdot{ }^{14 \mathrm{e}}$ Similarly, Fu's procedure uses the $\mathrm{PdCl}_{2}\left(\mathrm{PPh}_{3}\right)_{2} /$ Xantphos catalyst in DMA $/ \mathrm{H}_{2} \mathrm{O}$ solvent in the presence of $\mathrm{K}_{2} \mathrm{CO}_{3}$ base. ${ }^{14 \mathrm{~b}}$ Both alkylations require blue light irradiation for appropriate excitation of the photocatalytic system.

We started our investigation with the optimization of the reaction of styrene (1a) and trifluoroethyl iodide (2) using palladium(II)-Xantphos catalyst systems. The reactions were irradiated by $440-445 \mathrm{~nm}$ LEDs for $18 \mathrm{~h}$ at $25{ }^{\circ} \mathrm{C}$ and analyzed by GC-MS. We found that the Gevorgyan-type $\mathrm{Pd}(\mathrm{OAc})_{2}-$ Xantphos photocoupling system ${ }^{14 \mathrm{e}}$ works effi-

Received: September 11, 2020

Published: October 1, 2020 
ciently in benzene in the desired trifluoroethylation and provides the expected product $\mathbf{3 a}$ in complete conversion. In contrast, Fu's conditions ${ }^{14 \mathrm{~b}}$ were not suitable for the fluoroalkylation, which shows system sensitivity of the coupling partner and indicates the necessity of fine-tuning of the reaction conditions. After finding the appropriate catalytic system we aimed to fine-tune the reaction conditions to reach more suitable reaction conditions for the fluoroalkylation of styrenes. In these experiments we focused on lowering the catalyst and base loadings, and solvent selection.

We found that the catalyst loading can be lowered in the case of the trifluoroethylation, but the minimum amount of needed $\mathrm{Pd}(\mathrm{OAc})_{2}$ catalyst for the reaction completion was 5 mol \%; further reduction of the catalyst loading significantly decreased the conversion (Table 1, entries 2-6). A control

Table 1. Fine-tuning of Photocatalytic Conditions ${ }^{a}$

\begin{tabular}{|c|c|c|c|}
\hline \multirow{3}{*}{$\begin{array}{c}\text { 1a } \\
\text { Entry }\end{array}$} & \multicolumn{2}{|c|}{$\begin{array}{c}5 \mathrm{~mol} \%[\mathrm{Pd}] \\
10 \mathrm{~mol} \% \text { Xantphos } \\
1.5 \text { equiv } \mathrm{Cs}_{2} \mathrm{CO}_{3} \\
\end{array}$} & \\
\hline & & $\begin{array}{l}\text { benzene, blue LEDs } \\
\text { Ar, } 25^{\circ} \mathrm{C}, 18 \mathrm{~h}\end{array}$ & \\
\hline & Catalyst & Solvent & Conv. \\
\hline 1 & $10 \mathrm{~mol} \% \mathrm{Pd}(\mathrm{OAc})$ & benzene & $100 \%^{b}$ \\
\hline 2 & $5 \mathrm{~mol} \% \mathrm{Pd}(\mathrm{OAc})_{2}$ & benzene & $100 \%$ \\
\hline 3 & $4 \mathrm{~mol} \% \mathrm{Pd}(\mathrm{OAc})_{2}$ & benzene & $99 \%$ \\
\hline 4 & $3 \mathrm{~mol} \% \operatorname{Pd}(\mathrm{OAc})_{2}$ & benzene & $89 \%$ \\
\hline 5 & $2 \mathrm{~mol} \% \mathrm{Pd}(\mathrm{OAc})_{2}$ & benzene & $38 \%$ \\
\hline 6 & $1 \mathrm{~mol} \% \mathrm{Pd}(\mathrm{OAc})_{2}$ & benzene & $12 \%$ \\
\hline 7 & $5 \mathrm{~mol} \% \mathrm{Pd}(\mathrm{OAc})_{2}$ & benzene & $0 \%^{c}$ \\
\hline 8 & $\mathrm{PdCl}_{2}$ & benzene & $0 \%$ \\
\hline 9 & $\mathrm{Pd}(\mathrm{acac})_{2}$ & benzene & $48 \%$ \\
\hline 10 & $\mathrm{Pd}(\mathrm{TFA})_{2}$ & benzene & $83 \%$ \\
\hline 11 & $\mathrm{Pd}_{2}(\mathrm{dba})_{3}$ & benzene & $27 \%$ \\
\hline 12 & $\mathrm{Pd}(\mathrm{OAc})_{2}$ & water & $7 \%$ \\
\hline 13 & $\mathrm{Pd}(\mathrm{OAc})_{2}$ & acetone & $40 \%$ \\
\hline 14 & $\mathrm{Pd}(\mathrm{OAc})_{2}$ & ethyl acetate & $46 \%$ \\
\hline 15 & $\mathrm{Pd}(\mathrm{OAc})_{2}$ & THF & $83 \%$ \\
\hline 16 & $\mathrm{Pd}(\mathrm{OAc})_{2}$ & chlorobenzene & $5 \%$ \\
\hline 17 & $\mathrm{Pd}(\mathrm{OAc})_{2}$ & toluene & $80 \%$ \\
\hline 18 & $\mathrm{Pd}(\mathrm{OAc})_{2}$ & BTF & $90 \%$ \\
\hline 19 & $\mathrm{Pd}(\mathrm{OAc})_{2}$ & cyclohexane & $75 \%$ \\
\hline
\end{tabular}

${ }^{a}$ Standard reaction conditions: styrene $(0.2 \mathrm{mmol})$, trifluoroethyliodide (1.5 equiv), $\mathrm{Cs}_{2} \mathrm{CO}_{3}$ (1.5 equiv), catalyst ( $5 \mathrm{~mol} \%$ ), ligand (10 $\mathrm{mol} \%)$ in $1 \mathrm{~mL}$ degassed benzene under $\mathrm{Ar}$ atmosphere, irradiated with single $10 \mathrm{~W} 440-445 \mathrm{~nm}$ LEDs at $25^{\circ} \mathrm{C}^{{ }^{b}} 3$ equiv of $\mathrm{Cs}_{2} \mathrm{CO}_{3}$ were used. ${ }^{c}$ In the dark.

experiment without any irradiation indicated that the light is essential for this transformation (Table 1, entry 7). Next, we tested different Pd sources, and we demonstrated that the use of $\mathrm{PdCl}_{2}$ could not result in any product; $\mathrm{Pd}_{2}(\mathrm{dba})_{3}$ and $\mathrm{Pd}(\mathrm{acac})_{2}$ were only moderately active in this reaction, and $\mathrm{Pd}(\mathrm{TFA})_{2}$ performed almost as good as $\mathrm{Pd}(\mathrm{OAc})_{2}$ (Table 1 , entries 8-11). Among the tested polar solvents water, acetone and ethyl acetate were relatively ineffective (Table 1 , entries 12-14), while in THF the reaction reached $83 \%$ conversion. Reactions performed in solvents similar to benzene gave versatile results: chlorobenzene was completely ineffective, while in toluene and benzotrifluoride (BTF) the coupling reaction gave $80 \%$ and $90 \%$ conversion respectively, which are good results but compared to benzene the transformation did not reach completion. In cyclohexane alongside the desired coupling iodocyclohexane was formed as a byproduct which made this solvent unsuitable (Table 1 , entry 19).

With the optimized conditions in hand first we investigated the generality of the trifluoroethylation reaction (Scheme 2).

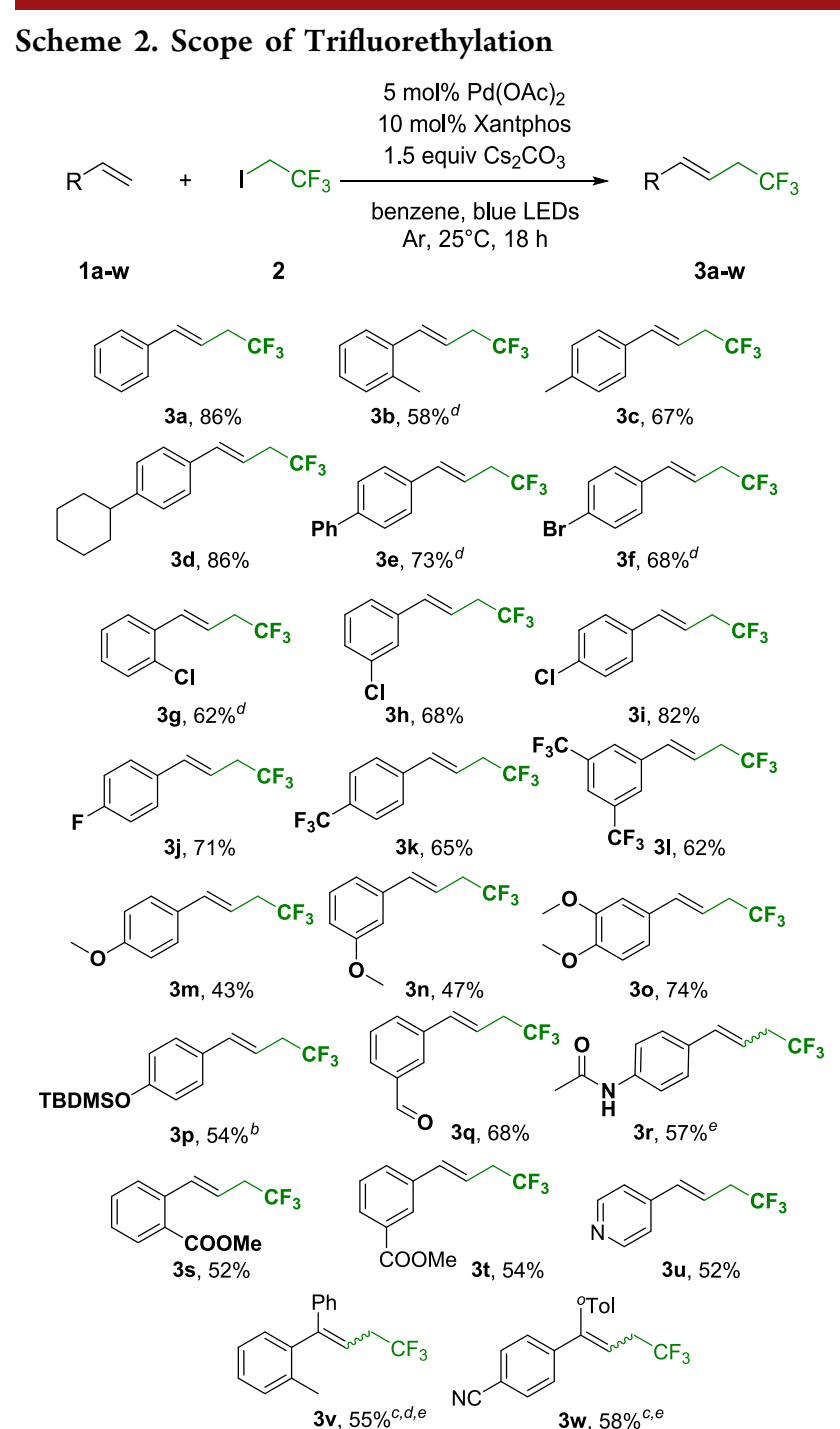

${ }^{a}$ Standard reaction conditions: substrate $(0.5 \mathrm{mmol})$, trifluoroethyl iodide (1.5 equiv), $\mathrm{Cs}_{2} \mathrm{CO}_{3}$ (1.5 equiv), $\mathrm{Pd}(\mathrm{OAc})_{2}(5 \mathrm{~mol} \%)$, and Xantphos (10 mol \%) was used in $2.5 \mathrm{~mL}$ degassed benzene under an $\mathrm{Ar}$ atmosphere, irradiated with single $10 \mathrm{~W} 440-445 \mathrm{~nm}$ LEDs at 25 ${ }^{\circ} \mathrm{C}$. ${ }^{b}$ The reaction time was $24 \mathrm{~h}$. ${ }^{c} 10 \mathrm{~mol} \%$ catalyst, $20 \mathrm{~mol} \%$ Xantphos and 3 equiv. base were used. ${ }^{d}$ Average of two reactions. ${ }^{e} E /$ $Z$ ratio 3 r 13:1; 3v 3:1; 3w: 33:1.

The transformation proceeded smoothly with styrene derivatives with electron-withdrawing and electron-donating groups as well, regardless of their position on the aromatic ring. We synthesized different alkyl (3b, 3c, 3d) and aryl (3e) derivatives in good yields, and the reaction worked efficiently with halogenated styrenes $(\mathbf{3} \mathbf{f}-\mathbf{j})$ and methoxy derivatives (3m, 3n, 3o) as well. The silyl protected phenol functional group is also tolerated under the reaction conditions, and product $3 \mathrm{p}$ was isolated in $54 \%$ yield after a $24 \mathrm{~h}$ reaction time. Aldehyde (3q), amide (3r) and ester (3s, 3t) derivatives were also prepared successfully from the corresponding styrene. In 
this series the pyridine derivative $(3 \mathbf{u})$ was also obtained in $52 \%$ yield. On the other hand, 1,1-diphenylethylene derivatives proved to be less reactive in this transformation. Therefore, increased catalyst and base loadings were necessary to accomplish the desired coupling. We managed to synthesize the $3 v$ and $3 \mathbf{w}$ derivatives in $55 \%$ and $58 \%$ yields, respectively.

Next, we broadened the scope of the photocatalytic fluoroalkylation method with versatile fluoroalkyl iodides (Scheme 3). We found that 1,1-difluoro-2-iodoethane is also capable of participating in the coupling reaction.

Scheme 3. Scope of Different Fluoroalkyl Iodides ${ }^{a}$

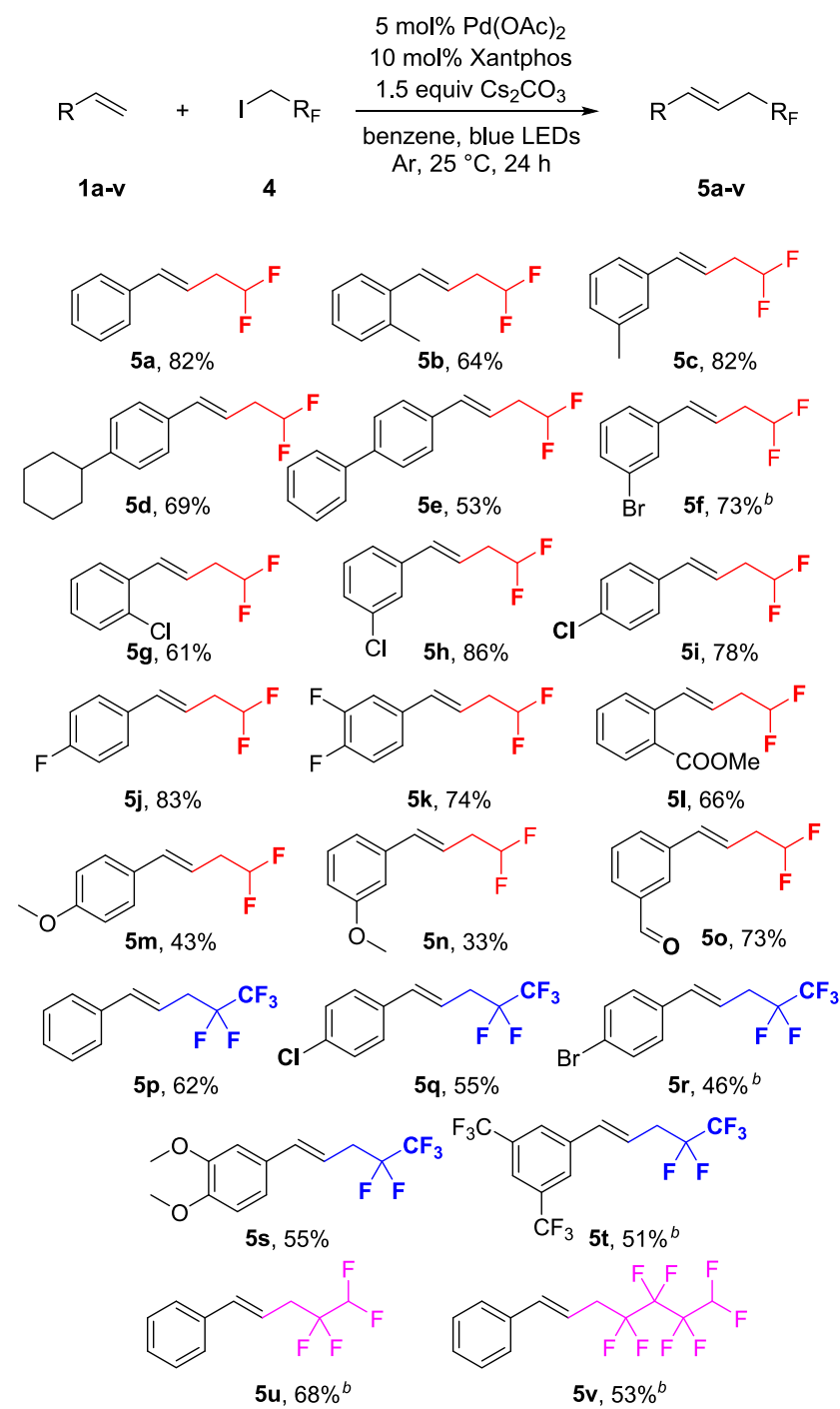

${ }^{a}$ Standard reaction conditions: substrate $(0.5 \mathrm{mmol})$, fluoroalkyl iodide (1.5 equiv), $\mathrm{Cs}_{2} \mathrm{CO}_{3}$ (1.5 equiv), $\mathrm{Pd}(\mathrm{OAc})_{2}$ (5 mol \%), Xantphos (10 mol \%) was used in $2.5 \mathrm{~mL}$ degassed benzene under $\mathrm{Ar}$ atmosphere, irradiated with single $10 \mathrm{~W} 440-445 \mathrm{~nm}$ LEDs at $25^{\circ} \mathrm{C}$. ${ }^{b}$ Average of two reactions.

This attracted our interest because the difluoromethyl moiety is a well-studied motif in medicinal chemistry. The difluoromethyl group is isosteric and isopolar with the $-\mathrm{OH}$ and $-\mathrm{SH}$ groups and can behave as a $\mathrm{H}$-donor as well. ${ }^{15}$ The preparation of difluoroethylated styrene derivatives is performed only through the functionalization of allylic halides with difluorocarbene sources, ${ }^{16}$ and direct difluoroethylation of terminal alkene is unprecedented.

Applying the previously used reaction conditions, we found that the coupling of 1,1-difluoro-2-iodoethane with styrene requires a $24 \mathrm{~h}$ reaction time to reach completion, and we could isolate the corresponding difluoroethylated styrene product (5a) in $82 \%$ yield. With the slightly modified procedure, 12 additional derivatives were prepared to explore the scope of the photocatalyzed coupling reaction. This transformation also possesses good functional group tolerance, and alkyl (5b, 5c, 5d), aryl (5e), halogen (5f-k), ester (51), methoxy (5m, 5n), and aldehyde (5o) derivatives were successfully synthesized.

Increasing further the versatility of the fluoroalkyl part we utilized $1 \mathrm{H}, 1 \mathrm{H}$-pentafluoropropyl iodide as a coupling partner, and we obtained the corresponding coupling products under the standard reaction conditions. In this case the pentafluoropropylated derivatives $(5 p-t)$ were isolated in $46-62 \%$ yield. Additionally, two other fluoralkyl iodides were also tested in this transformation, 1,1,2,2-tetrafluoro-3-iodopropane and $1 \mathrm{H}, 1 \mathrm{H}, 5 \mathrm{H}$-octafluoropentyl iodide, and successfully gave the desired coupled products (5u, 5v) in $68 \%$ and $53 \%$ yield, respectively, which demonstrates that longer fluorous chains are also applicable in this palladium-catalyzed photochemical transformation.

Results of the radical quenching and light on-off experiments ${ }^{17}$ support that the fluoroalkylation reaction follows the general mechanism of the palladium-catalyzed alkylations. ${ }^{14}$ The Xantphos- $\mathrm{Pd}(0)$ complex can be excited with blue light (440-460 nm), and then this Pd species reacts with fluoroalkyl iodide in the SET reaction, supposedly generating a Xantphos-Pd(I)-I and fluoroalkyl radical pair (the latter was trapped with TEMPO to prove its presence), ${ }^{17}$ which are in close proximity. Alkene reacts with this palladium(I) intermediate through insertion or radical addition, and then a $\beta$-hydrogen radical elimination could form the coupled styrene product and the common $\mathrm{H}-\mathrm{Pd}(\mathrm{II})-\mathrm{I}$. This latter species undergoes base-assisted reductive elimination to produce Xantphos-Pd(0), ready for the next catalytic cycle.

In conclusion we developed a visible light driven palladiumcatalyzed Heck-type coupling between styrenes and fluoroalkyl iodides at room temperature, which enables the introduction of versatile fluoroalkyl chains into terminal alkene functionality. A series of styrene derivatives were subjected to the present reaction conditions and formed the corresponding fluoroalkyl derivatives in good yields. In our synthetic studies five different fluoroalkyl iodides were successfully utilized. This method offers an efficient disconnection to incorporate fluorinecontaining functional groups into styrene derivatives, which could serve as a useful derivatization method to obtain fluoroalkenylated compounds.

\section{ASSOCIATED CONTENT}

\section{Supporting Information}

The Supporting Information is available free of charge at https://pubs.acs.org/doi/10.1021/acs.orglett.0c03043.

General information, synthesis procedures, characterizations of products $\left({ }^{1} \mathrm{H},{ }^{13} \mathrm{C},{ }^{19} \mathrm{~F}\right.$ NMR, IR, HRMS $)$, and spectra (PDF) 


\section{AUTHOR INFORMATION}

\section{Corresponding Author}

Zoltán Novák - ELTE "Lendület" Catalysis and Organic Synthesis Research Group, Institute of Chemistry, Eötvös Loránd University, Faculty of Science, H-1117 Budapest, Hungary; 이이.org/0000-0001-5525-3070; Email: novakz@elte.hu

\section{Authors}

Réka Adamik - ELTE "Lendület" Catalysis and Organic Synthesis Research Group, Institute of Chemistry, Eötvös Loránd University, Faculty of Science, H-1117 Budapest, Hungary

Tamás Földesi - ELTE "Lendület" Catalysis and Organic Synthesis Research Group, Institute of Chemistry, Eötöos Lorand University, Faculty of Science, H-1117 Budapest, Hungary

Complete contact information is available at:

https://pubs.acs.org/10.1021/acs.orglett.0c03043

\section{Notes}

The authors declare no competing financial interest.

\section{ACKNOWLEDGMENTS}

This research was funded by the National Research, Development and Innovation Office (K132077 and KH125230). This work was completed in the ELTE Institutional Excellence Program (1783-3/2018/FEKUTSRAT), Cooperation Excellence Program with Research Centre for Natural Sciences and the ÚNKP-19-3 New National Excellence program supported by the Hungarian Ministry of Human Capacities (A.R.). The authors are thankful for the analytical measurements by László Burai, Soma Szabó, Márton Zwillinger, and Tamás Gáti at Servier Research Institute of Medicinal Chemistry and the donation of some styrene substrates. The authors thank Dr. Tibor Soós and Mr. Máté Berta (Research Centre for Natural Sciences, Budapest, Hungary) for the NMR measurements and Attila Kiss (University of Debrecen) for HRMS measurements.

\section{REFERENCES}

(1) (a) Shimizu, M.; Hiyama, T. Modern Synthetic Methods for Fluorine-Substituted Target Molecules. Angew. Chem., Int. Ed. 2005, 44, 214-231. (b) Muller, K.; Faeh, C.; Diederich, F. Fluorine in Pharmaceuticals: Looking Beyond Intuition. Science 2007, 317, 18811886. (c) Johnson, B. M.; Shu, Y.-Z.; Zhuo, X.; Meanwell, N. A. Metabolic and Pharmaceutical Aspects of Fluorinated Compounds. J. Med. Chem. 2020, 63, 6315-6386. (d) Ojima, I. Fluorine in Medicinal Chemistry and Chemical Biology; Wiley-Blackwell: 2009. (e) Wang, J.; Sánchez-Roselló, M.; Aceña, J. L.; del Pozo, C.; Sorochinsky, A. E.; Fustero, S.; Soloshonok, V. A.; Liu, H. Fluorine in pharmaceutical industry: fluorine-containing drugs introduced to the market in the last decade (2001-2011). Chem. Rev. 2014, 114, 2432-2506. (f) Zhou, Y.; Wang, J.; Gu, Z.; Wang, S.; Zhu, W.; Aceña, J. L.; Soloshonok, V. A.; Izawa, K.; Liu, H. Next Generation of FluorineContaining Pharmaceuticals, Compounds Currently in Phase II-III Clinical Trials of Major Pharmaceutical Companies: New Structural Trends and Therapeutic Areas. Chem. Rev. 2016, 116, 422-518.

(2) (a) Merino, E.; Nevado, C. Addition of $\mathrm{CF}_{3}$ across Unsaturated Moieties: A Powerful Functionalization Tool. Chem. Soc. Rev. 2014, 43, 6598-6608. (b) Li, G.; Zhang, C.; Song, C.; Ma, Y. Progress in Copper-Catalyzed Trifluoromethylation. Beilstein J. Org. Chem. 2018, 14, 155-181. (c) Tomashenko, O. A.; Grushin, V. V. Aromatic trifluoromethylation with metal complexes. Chem. Rev. 2011, 111, 4475-4521. (d) Studer, A. A "renaissance" in radical trifluoromethylation. Angew. Chem., Int. Ed. 2012, 51, 8950-8958. (e) Besset, T.;
Schneider, C.; Cahard, D. Tamed arene and heteroarene trifluoromethylation. Angew. Chem., Int. Ed. 2012, 51, 5048-5050. (f) Bizet, V.; Besset, T.; Ma, J.-A.; Cahard, D. Recent progress in asymmetric fluorination and trifluoromethylation reactions. Curr. Top. Med. Chem. 2014, 14, 901-940. (g) Liu, X.; Xu, C.; Wang, M.; Liu, Q. Trifluoromethyltrimethylsilane: nucleophilic trifluoromethylation and beyond. Chem. Rev. 2015, 115, 683-730. (h) Alonso, C.; de Marigorta, E. M.; Rubiales, G.; Palacios, F. Carbon Trifluoromethylation Reactions of Hydrocarbon Derivatives and Heteroarenes. Chem. Rev. 2015, 115, 1847-1935. (i) Egami, H.; Sodeoka, M. Trifluoromethylation of alkenes with concomitant introduction of additional functional groups. Angew. Chem., Int. Ed. 2014, 53, 82948308. (j) Besset, T.; Poisson, T.; Pannecoucke, X. Direct vicinal difunctionalization of alkynes: an efficient approach towards the synthesis of highly functionalized fluorinated alkenes. Eur. J. Org. Chem. 2015, 2015, 2765-2789.

(3) (a) Tóth, B. L.; Kovács, S.; Sályi, G.; Novák, Z. Mild and Efficient Palladium-Catalyzed Direct Trifluoroethylation of Aromatic Systems by C-H Activation. Angew. Chem., Int. Ed. 2016, 55, 19881992. (b) Tolnai, G. L.; Székely, A.; Makó, Z.; Gáti, T.; Daru, J.; Bihari, T.; Stirling, A.; Novák, Z. Efficient Direct 2,2,2-Trifluoroethylation of Indoles via $\mathrm{C}-\mathrm{H}$ Functionalization. Chem. Commun. 2015, 51, 4488-4491. (c) Maraswami, M.; Pankajakshan, S.; Chen, G.; Loh, T.-P. Palladium-Catalyzed Direct C-H Trifluoroethylation of Aromatic Amides. Org. Lett. 2017, 19, 4223-4226.

(4) (a) Barata-Vallejo, S.; Bonesi, S. M.; Postigo, A. Photocatalytic fluoroalkylation reactions of organic compounds. Org. Biomol. Chem. 2015, 13, 11153-11183. (b) Koike, T.; Akita, M. Fine Design of Photoredox Systems for Catalytic Fluoromethylation of CarbonCarbon Multiple Bonds. Acc. Chem. Res. 2016, 49, 1937-1945.

(5) Feng, Z.; Min, Q.-Q.; Zhao, H.-Y.; Gu, J.-W.; Zhang, X. A General Synthesis of Fluoroalkylated Alkenes by Palladium-Catalyzed Heck-Type Reaction of Fluoroalkyl Bromides. Angew. Chem., Int. Ed. 2015, 54, 1270-1274.

(6) Miyake, Y.; Ota, S.; Nishibayashi, Y. Copper-Catalyzed Nucleophilic Trifluoromethylation of Allylic Halides: A Simple Approach to Allylic Trifluoromethylation. Chem. - Eur. J. 2012, 18, 13255-13258.

(7) (a) Xu, J.; Fu, Y.; Luo, D.-F.; Jiang, Y.-Y.; Xiao, B.; Liu, Z.-J.; Gong, T.-J.; Liu, L. Copper-Catalyzed Trifluoromethylation of Terminal Alkenes through Allylic C-H Bond Activation. J. Am. Chem. Soc. 2011, 133, 15300-15303. (b) Parsons, A. T.; Buchwald, S. L. Copper-Catalyzed Trifluoromethylation of Unactivated Olefins. Angew. Chem., Int. Ed. 2011, 50, 9120-9123.

(8) (a) Zhao, Y.; Hu, J. Palladium-Catalyzed 2,2,2-Trifluoroethylation of Organoboronic Acids and Esters. Angew. Chem., Int. Ed. 2012, 51, 1033-1036. (b) Zhang, Y.; Du, H.; Zhu, M.; Li, J.; Zou, D.; Wu, Y.; Wu, Y. Copper-Catalyzed Decarboxylative Trifluoroethylation of Cinnamic Acids. Tetrahedron Lett. 2017, 58, 880-883.

(9) (a) Kreis, L. M.; Krautwald, S.; Pfeiffer, N.; Martin, R. E.; Carreira, E. M. Photocatalytic Synthesis of Allylic Trifluoromethyl Substituted Styrene Derivatives in Batch and Flow. Org. Lett. 2013, 15, 1634-1637. (b) Li, L.; Huang, M.; Liu, C.; Xiao, J.-C.; Chen, Q.Y.; Guo, Y.; Zhao, Z.-G. 2,2,2-Trifluoroethylation of Styrenes with Concomitant Introduction of a Hydroxyl Group from Molecular Oxygen by Photoredox Catalysis Activated by Visible Light. Org. Lett. 2015, 17, 4714-4717. (c) Roh, G.; Iqbal, N.; Cho, E. J. Trifluoroethylation of Alkynes: Synthesis of Allylic- $\mathrm{CF}_{3}$ Compounds by Visible-Light Photocatalysis. Chin. J. Chem. 2016, 34, 459-464. (d) Straathof, N. J. W.; Cramer, S. E.; Hessel, V.; Noël, T. Practical Photocatalytic Trifluoromethylation and Hydrotrifluoromethylation of Styrenes in Batch and Flow. Angew. Chem., Int. Ed. 2016, 55, $15549-15553$.

(10) Mészáros, Á.; Székely, A.; Stirling, A.; Novák, Z. Design of Trifluoroalkenyl Iodonium Salts for a Hypervalency-Aided Alkenylation-Cyclization Strategy: Metal-Free Construction of Aziridine Rings. Angew. Chem., Int. Ed. 2018, 57, 6643-6647.

(11) (a) Varga, B.; Gonda, Zs.; Tóth, B.; Kotschy, A.; Novák, Z. Development of Ni-Ir dual photocatalytic Liebeskind coupling of 
sulfonium salts for the synthesis of 2-benzylpyrrolidines. Eur. J. Org. Chem. 2020, 2020, 1466-1471. (b) Földesi, T.; Adamik, R.; Sipos, G.; Nagy, B.; Tóth, B. L.; Bényei, A.; Szekeseres, K.; Láng, Gy.; Demeter, A.; Peelen, T. J.; Novák, Z. Design and application of diimine-based copper(I) complexes in photoredox catalysis. Org. Biomol. Chem. 2019, 17, 8343-8347.

(12) (a) Handbook of Organopalladium Chemistry for Organic Synthesis; Negishi, E., de Meijere, A., Eds.; John Wiley \& Sons: New York, NY, 2002. (b)Metal-Catalyzed Cross-Coupling Reactions; de Meijere, A., Diederich, F., Eds.; Wiley-VCH: Weinheim, 2004.

(13) (a) Bloome, K. S.; McMahen, R. L.; Alexanian, E. J. PalladiumCatalyzed Heck-Type Reactions of Alkyl Iodides. J. Am. Chem. Soc. 2011, 133, 20146-20148. (b) McMahon, C. M.; Alexanian, E. J. Palladium-Catalyzed Heck-Type Cross-Couplings of Unactivated Alkyl Iodides. Angew. Chem., Int. Ed. 2014, 53, 5974-5977.

(14) (a) Kurandina, D.; Parasram, M.; Gevorgyan, V. Visible LightInduced Room-Temperature Heck Reaction of Functionalized Alkyl Halides with Vinyl Arenes/Heteroarenes. Angew. Chem., Int. Ed. 2017, 56, 14212-14216. (b) Wang, G.-Z.; Shang, R.; Cheng, W.-M.; Fu, Y. Irradiation-Induced Heck Reaction of Unactivated Alkyl Halides at Room Temperature. J. Am. Chem. Soc. 2017, 139, 18307-18312. (c) Wang, G.-Z.; Shang, R.; Fu, Y. Irradiation-Induced PalladiumCatalyzed Decarboxylative Heck Reaction of Aliphatic N-(Acyloxy)phthalimides at Room Temperature. Org. Lett. 2018, 20, 888-891. (d) Koy, M.; Sandfort, F.; Tlahuext-Aca, A.; Quach, L.; Daniliuc, C. G.; Glorius, F. Palladium-Catalyzed Decarboxylative Heck-Type Coupling of Activated Aliphatic Carboxylic Acids Enabled by Visible Light. Chem. - Eur. J. 2018, 24, 4552-4555. (e) Kurandina, D.; Rivas, M.; Radzhabov, M.; Gevorgyan, V. Heck Reaction of Electronically Diverse Tertiary Alkyl Halides. Org. Lett. 2018, 20, 357-360. (f) Zhao, B.; Shang, R.; Wang, G.-Z.; Wang, S.; Chen, H.; Fu, Y. Palladium-Catalyzed Dual Ligand-Enabled Alkylation of Silyl Enol Ether and Enamide under Irradiation: Scope, Mechanism, and Theoretical Elucidation of Hybrid Alkyl Pd(I)-Radical Species. ACS Catal. 2020, 10, 1334-1343. (g) Chuentragool, P.; Kurandina, D.; Gevorgyan, V. Catalysis with Palladium Complexes Photoexcited by Visible Light. Angew. Chem., Int. Ed. 2019, 58, 11586-11598. (h) Xing, W.-L.; Shang, R.; Wang, G.-Z.; Fu, Y. Visible Light-Induced Palladium-Catalyzed Ring Opening $\beta$-H Elimination and Addition of Cyclobutanone Oxime Esters. Chem. Commun. 2019, 55, 1429114294. (i) Feng, L.; Guo, L.; Yang, C.; Zhou, J.; Xia, W. Visible-LightInduced Palladium-Catalyzed Intermolecular Narasaka-Heck Reaction at Room Temperature. Org. Lett. 2020, 22, 3964-3968.

(15) (a) Erickson, J. A.; McLoughlin, J. I. Hydrogen Bond Donor Properties of the Difluoromethyl Group. J. Org. Chem. 1995, 60, 1626-1631. (b) Narjes, F.; Koehler, K. F.; Koch, U.; Gerlach, B.; Colarusso, S.; Steinkühler, C.; Brunetti, M.; Altamura, S.; Francesco, R. D.; Matassa, V. G. A Designed P1 Cysteine Mimetic for Covalent and Non-Covalent Inhibitors of HCV NS3 Protease. Bioorg. Med. Chem. Lett. 2002, 12, 701-704. (c) Prakash, G. K. S.; Mandal, M.; Schweizer, S.; Petasis, N. A.; Olah, G. A. Stereoselective Synthesis anti- $\alpha$-(Difluoromethyl)- $\beta$-Amino Alcohols by Boronic Acid Based Three-Component Condensation. Stereoselective Preparation of (2S,3R)-Difluorothreonine. J. Org. Chem. 2002, 67, 3718-3723. (d) Chowdhury, M. A.; Abdellatif, K. R. A.; Dong, Y.; Das, D.; Suresh, M. R.; Knaus, E. E. Synthesis of Celecoxib Analogues Possessing a NDifluoromethyl-1,2-Dihydropyrid-2-One 5-Lipoxygenase Pharmacophore: Biological Evaluation as Dual Inhibitors of Cyclooxygenases and 5-Lipoxygenase with Anti-Inflammatory Activity. J. Med. Chem. 2009, 52, 1525-1529.

(16) (a) Burton, D. J.; Hartgraves, G. A. The Preparation of $\mathrm{HCF}_{2} \mathrm{CdX}$ and $\mathrm{HCF}_{2} \mathrm{ZnX}$ via Direct Insertion into the Carbon Halogen Bond of $\mathrm{CF}_{2} \mathrm{HY}(\mathrm{Y}=\mathrm{Br}, \mathrm{I})$. J. Fluorine Chem. 2007, 128, 1198-1215. (b) Aikawa, K.; Ishii, K.; Endo, Y.; Mikami, K. CopperCatalyzed Allylic Difluoromethylation of Allyl Carbonates with (Difluoromethyl)zinc Reagent. J. Fluorine Chem. 2017, 203, 122129. (c) Gu, Y.; Lu, C.; Gu, Y.; Shen, Q. Ligand-Controlled CopperCatalyzed Highly Regioselective Difluoromethylation of Allylic
Chlorides/Bromides and Propargyl Bromides. Chin. J. Chem. 2018, $36,55-58$.

(17) For details, see Supporting Information. 